\title{
Una ciudad de la Marca Media: Vascos (Toledo)
}

\author{
Ricardo Izquierdo Benito *
}

\begin{abstract}
RESUMEN
Los restos del yacimiento conocido como Vascos corresponden a una pequeña ciudad de la Marca Media de al-Andalus, de la que no se tienen referencias escritas, aunque se han conservado importantes restos arquitectónicos. Los resultados de las excavaciones arqueológicas que se han desarrollado en el lugar durante varios años permiten establecer, como hipótesis, el sentido de la fundación de esta ciudad, y lo que pudo haber sido su evolución cronológica.
\end{abstract}

PALABRAS CLAVE: Vascos, ciudad, al Andalus, Marca Media

Los restos del yacimiento arqueológico conocido como la ciudad de Vascos, corresponden a una antigua ciudad hispanomusulmana actualmente despoblada. Se encuentra localizada en la provincia de Toledo, en su parte oeste, muy próxima al límite de la provincia de Cáceres, en el término municipal de Navalmoralejo.

Ubicada en un lugar apartado, que la ha mantenido alejada de las principales vías de comunicación que discurrían por la zona -lo cual, en gran medida, ha contribuido a que el lugar no haya sido expoliado de una manera intensiva-, ha conservado en bastante buen estado un importante conjunto arquitectónico (muralla, alcazaba, etc.), único en su género, que

\begin{abstract}
The archaeological remains preserved in the site of Vascos correspond to a small town in the Marca media of al-Andalus, with important architectonic structures, altough not mentioned in the written sources. The results of archaeological excavations carried out for some years in the place allow us to pose hipothesis concerning the reasons of their foundation and its possible chronological evolution.
\end{abstract}

KEY WORDS: Vascos, town, al-Andalus, Marca Media.

fue declarado monumento histórico-artístico en el año 1931, por lo que en la actualidad tiene la condición de BIC (Bien de Interés Cultural).

Como la mayoría de las ciudades fundadas por los musulmanes, se encuentra enclavada en una zona de difícil acceso, asentada en un terreno de granitos hercinianos, y rodeada por el profundo y escarpado cauce del río Huso en su parte norte y este, que le sirve de defensa natural. Por su lado oeste desciende un pequeño valle por el cual corre, en años húmedos, el arroyo llamado de la Mora o de los Baños. La parte sur, por la que actualmente se accede al yacimiento, es la que se abre a un espacio más llano.

* Universidad de Castilla la Mancha 
La topografía de su interior presenta muchas irregularidades. Desde la parte sur, la más elevada, el terreno desciende gradualmente en dirección norte, con una inclinación de este a oeste, formando, en algunos lugares, acusados desniveles y cuestas muy pendientes. Tras formar una vaguada en la que el espacio queda algo más allanado, nuevamente se eleva en un pequeño cerro, de abrupta caída al río Huso, sobre el que se levantan los restos de la alcazaba.

Los vestigios mejor conservados, y los que dotan al conjunto de su carácter monumental y sorprenden al visitante, son aquellos que constituyen los elementos defensivos y militares de la ciudad: la sólida muralla que la circunda y el complejo de la alcazaba. Extramuros existen un arrabal y dos cementerios.

El trazado de la muralla de Vascos, que se adapta al terreno bordeando los lugares más escarpados, presenta una forma ligeramente ovalada, con una dirección norte-sur, y delimita un espacio interior -la madina- de unas ocho hectáreas de extensión, en el que se pueden observar, en superficie, los restos de algunas construcciones.

La muralla tiene una anchura media de 1,5 $m$ y se encuentra bastante bien conservada, sobre todo en los sectores oeste y sur y parte del este. Se asienta directamente sobre la roca, sin ningún tipo de cimentación, y solamente presenta, en algunos tramos, pequeños escalones de reforzamiento o zarpas en la base. Al exterior, con una distancia de separación muy desigual -debido a la topografía del terreno-, tiene varios torreones de planta cuadrada.

Aunque esta muralla ofrece poca altura en algunos tramos, ello no parece señalar que haya sido desmochada intencionadamente en algún momento para reaprovechar la piedra, sino que su parte superior estaría recrecida con tapial, de muy mala calidad, por lo que no se ha conservado resto alguno. También es posible que estuviese coronada por almenas, como atestiguan las que todavía se conservan junto a la puerta sur.
A lo largo de su trazado la muralla presenta varios tipos de construcción -unos de mejor calidad que otros- que, más que indicar distintos momentos cronológicos o reconstrucciones posteriores, posiblemente se deban a la intervención de diferentes cuadrillas, que trabajarían simultáneamente -ante la urgencia de cerrar el perímetro urbano- pero empleando técnicas distintas, cada una de ellas, aunque parecidas.

Se conservan los restos de dos puertas -la sur y la oeste, así denominadas por su ubicación-y de cinco portillos. Las puertas se encuentran, lógicamente, en las zonas de más fácil acceso, y ambas presentan el mismo esquema arquitectónico: entrada directa, sin recodos, -posiblemente adintelada-, cerrada con puerta de dos batientes, y defendida por dos torreones exteriores a cada lado.

La puerta oeste, junto con el tramo de muralla en el que se encuentra inserta, es de construcción más sólida, de sillares bien escuadrados. Su parte superior está derrumbada, aunque por los restos conservados parece deducirse que se encontraría adintelada. Lo destacable es que en los sillares de su cara exterior se talló un arco de herradura, no como elemento arquitectónico sino como elemento decorativo.

La denominada puerta sur, está construida también con materiales sólidos pero de peor calidad, y tiene asimismo completamente derrumbada su parte superior, por lo que no se puede precisar con exactitud si se encontraba adintelada o rematada en un arco. En el lienzo de muralla próximo a esta puerta se conservan los restos de unas posibles almenas.

De los cinco portillos, dos se encuentran perfectamente conservados -rematados en su parte superior en sólidos dinteles- y los otros tres están derrumbados pero serían de características constructivas similares. Estos portillos se utilizarían, entre otras funciones, según su posición, para poder salir a coger agua, para sacar las basuras fuera de la ciudad y para servir de cauce natural de evacuación de las aguas de llu- 
via, aparte de poder entrar y salir por ellos sin necesidad de tener que utilizar las puertas principales. Todos ellos se encuentran defendidos, al exterior, por un torreón de la muralla.

La alcazaba de Vascos -residencia del gobernador y de la tropa que estaría a su mandose asienta en el pequeño cerro localizado en el extremo noroeste de la ciudad, en una posición estratégica, dominando gran parte de ésta y de los alrededores. Por su lado norte era prácticamente inaccesible, pues se encuentra protegida por un profundo barranco de abrupta caída al río Huso. Todo el conjunto de la alcazaba se excavó entre los años 1995 y 200 I, habiéndose recuperado muchas zonas que se encontraban completamente ocultas por derrumbes y quedando al descubierto un complejo formado por varios recintos que corresponden a diferentes momentos de la ampliación del primitivo reducto superior. Nos encontramos así ante uno de los pocos casos de alcazaba andalusí excavada en su integridad.

El recinto principal, y más antiguo, está ubicado en la parte más alta del cerro y originariamente tuvo una barbacana defensiva en su parte delantera. Es de forma ligeramente triangular y tiene una superficie de unos $2.000 \mathrm{~m}^{2}$. Se encuentra rodeado por una muralla, construida de sillares en su cara exterior y de mampostería en la interior, cuyo trazado, en su mayor parte, todavía se conserva. Es posible que, en algunos de los tramos que dan hacia el río estuviese recrecida con tapial que ha desaparecido.

Tiene un total de I I torreones, todos ellos localizados en los tramos oeste y sur, los orientados hacia la ciudad. En general, la construcción no es de muy buena calidad, especialmente en algunos tramos, lo que tal vez nos esté reflejando una urgencia de su levantamiento tras alguna destrucción violenta. En su parte delantera este recinto estaba protegido por una barbacana cerrada, constituida por un alto muro de bloques de piedra, rematado en tapial de buena calidad, el único que en toda la ciudad se ha conservado en parte.

A esta barbacana se accedía por una puerta que se abre en el lado oeste, desde la que arrancaba una rampa que conducía a la puerta del recinto principal, al que se entraba tras subir cinco escalones que posiblemente se añadieron en un momento posterior. Esta puerta está flanqueada y defendida por dos altos torreones, y se encontraría rematada por un arco de herradura -hoy derrumbado-, del cual se conservan los dos salmeres in-situ. En la parte norte de este recinto existe un portillo que, por su ubicación, no serviría tanto para descender al río, que se encuentra en un desnivel muy acusado, sino más bien para poder salir de la alcazaba en caso de tener que abandonarla precipitadamente. Se trataría, por tanto, de una salida de emergencia.

En el interior del recinto principal, antes de llevarse a cabo las excavaciones no se observaban superficialmente restos de edificaciones, excepto un aljibe cubierto con bóveda de cañón de sillarejo, que serviría para el almacenamiento de agua de lluvia necesaria para abastecer a los residentes en la fortaleza. Tras los trabajos arqueológicos han salido a la luz los restos de diversas edificaciones, bastante degradadas, cuya funcionalidad originaria es difícil poder precisar. Se trata, en su mayor parte, de pequeñas dependencias individualizadas que, al encontrarse en un espacio destinado a desempeñar funciones eminentemente militares, podrían haber servido para albergar a la tropa allí establecida y como zonas de almacenamiento de víveres y pertrechos. El complejo que se localiza en la parte central, por su ubicación y su configuración espacial con un mayor sentido de casa, tal vez puede corresponder a la vivienda del gobernador. Por su características constructivas, de sólidos sillares, el edificio alargado que se adosa a la muralla en su tramo sur, pudo haber tenido un cierto carácter "oficial", tal vez una sala de recepciones.

El acceso por la parte este se desarrollaba a través de una calle que asciende desde la vaguada y quedaba controlada por una de las torres de la alcazaba. Tuerce hacia la derecha en un tramo en el que la roca ha sido tallada para formar unos escalones. Este tramo quedaba cortado por una puerta que, estando cerrada, impedía el acceso al interior de un recinto formado en su parte este por un muro 
de mampostería, recrecido de tapial, que arranca del torreón más oriental de la muralla de la alcazaba. Ese recinto quedaba perfectamente controlado por este torreón. Una vez en el interior del mismo, se constituye un pasillo que gira hacia la izquierda y discurre paralelo a la muralla de la alcazaba, en parte tallado en la roca y en parte protegido por muretes de mampostería. Todo aquel que circulase por él estaba totalmente controlado desde la parte superior de la muralla de la alcazaba. Era, por tanto, un acceso muy vigilado y protegido, para evitar la entrada violenta de un hipotético enemigo que quisiese acceder al interior del núcleo principal de la alcazaba por aquel sector.

Este pasillo desemboca en otra puerta por la que se accedía a un gran espacio que, como ya hemos señalado, durante los primeros tiempos funcionaría como una barbacana y en el que posteriormente se construyó una mezquita que más adelante describiremos.

La parte oeste del complejo de la alcazaba está compuesta por dos zonas diferenciadas que fueron también añadidas con posterioridad, aunque al mismo tiempo: un recinto de entrada y un pequeño barrio. En primer lugar se encuentra un recinto de acceso previo a la rampa que conduce a la parte superior de la alcazaba. De tal manera que este nuevo recinto servía de protección al núcleo principal de la alcazaba: era preciso tener que pasar por él para poder acceder a aquélla. Y, además, había que cruzar dos puertas: la de acceso desde el exterior -que se construyó nueva-y, una vez dentro, la que ya existía de acceso a la rampa y a la barbacana/mezquita. Es de señalar que este recinto estaba completamente colmatado de piedras procedentes de derrumbes de la parte superior y su limpieza supuso su total recuperación, así como la de las dos puertas señaladas que se encontraban completamente ocultas.

Al norte de este espacio se encuentra otra zona, protegida por una muralla de mampostería, que muy posiblemente corresponde a un barrio anejo a la alcazaba, aunque no parece que tuviese conexión directa con ella. Esta zona también estaba completamente cubierta por los derrumbes que se habían producido desde la parte alta de la alcazaba. Una vez que se procedió a su limpieza y excavación, se pudo comprobar que en aquel recinto se conservaban los restos de algunos edificios que tampoco parecen corresponderse estrictamente con viviendas, pues no tienen los consabidos patios. Son simplemente habitaciones rectangulares, algunas exentas y otras adosadas. Muy posiblemente se trate de los lugares de alojamiento de la tropa que, por un aumento de la misma, en un momento de máxima necesidad defensiva, no habría tenido cabida en el recinto principal, por lo que fue necesario levantar este pequeño barrio, que también se protegió con una muralla, para acoger a aquel contingente militar complementario.

Como todos los cementerios de las ciudades musulmanas, los dos cementerios de Vascos se localizan extramuros, no muy alejados y se distinguen por los restos de muchas sepulturas que todavía se pueden observar en superficie, entre los que destacan los cipos, es decir, las piedras alargadas colocadas verticalmente en las esquinas de algunas tumbas. El cementerio de la zona sur parece de extensión considerable, aunque está en gran parte destruido por las labores de arado. El de la zona oeste es más reducido, pero, al localizarse en una zona de difícil acceso, los enterramientos se encuentran mejor conservados. Desde la ladera del cerro en la que éste se ubica se divisa la ciudad. Por las inmediaciones de ambos cementerios pasarían los dos principales caminos, hoy perdidos, que conducirían a las puertas de ésta.

Los baños de Vascos se encuentran en el arrabal, muy cerca de la puerta oeste, junto al denominado arroyo de la Mora que originariamente les surtiría de agua. Antes de comenzar los trabajos de excavación solamente eran visibles en superficie los restos de dos pequeños recintos adosados y abovedados, hundida la bóveda de uno de ellos. Aunque aquellos restos -conocidos popularmente como "el baño de la Mora"- no se sabía con exactitud a qué podían corresponder, su excavación nos proporcionó la planta de unos baños típicamente musulmanes, con las dependencias características de este tipo de establecimientos: vestua- 
rio (bait al-maslaj) con un banco de piedra alrededor, sala del baño frío (bait al-barid) cubierta con techumbre de teja, sala del baño templado (bait al-wastani) abovedada, sala del baño caliente (bait al-sajun) también abovedada y con el suelo hueco y la leñera con los restos del horno. Aparte de todas estas dependencias, imprescindibles en los baños islámicos, también existe otra pequeña habitación -cuya exacta función desconocemos- a la que se accedía desde el vestuario a través de un estrecho pasillo.

Muy posiblemente nos encontremos ante los restos de unos modestos baños públicos, localizados en el arrabal de la ciudad y junto a una de las puertas de acceso a la misma. Una ubicación similar también se ha observado en otros baños de otras ciudades andalusíes. Los principales usuarios serían los habitantes del arrabal, aunque cabe pensar que también serían frecuentados por los viajeros que llegasen a Vascos y que, antes de entrar en la ciudad y acudir a la mezquita, se lavarían, descansarían y purificarían en estos baños. Su proximidad a un arroyo está, evidentemente, en relación con el imprescindible abastecimiento de agua.

No sabemos si en el interior del recinto amurallado habrían existido otros baños, lo que sería difícil dado las dificultades de aprovisionamiento de agua que podrían haber tenido. Por ello, es posible que estos baños hubiesen sido los únicos de Vascos y, por tanto, que la mayor parte de su población los hubiese frecuentado, convirtiéndolos así en uno de los recintos de mayor actividad social de toda la ciudad.

De las dos mezquitas excavadas en Vascos, una, de pequeñas dimensiones, se encuentra en la vaguada al pie de la alcazaba, junto a una serie de edificios que allí se levantaron, y la otra -a la que ya nos hemos referido-, de amplitud mucho mayor, en el recinto delantero de la alcazaba que previamente pudo haber constituido una barbacana defensiva.

La mezquita pequeña presenta una planta cuadrada/trapezoidal, compuesta solamente por dos dependencias, de parecida superficie, comu- nicadas entre sí por una puerta interior, abierta en la parte central del muro de separación de ambas.

La dependencia situada al norte, a la que se accedía desde la calle, es de planta irregular y estuvo cubierta con un tejado de tejas. No sabemos la función que este espacio pudo haber desempeñado originariamente, si fue simplemente un recinto previo de acceso a la sala de oración principal -en el que se realizasen las abluciones- o si también se utilizó como lugar de oración y, por consiguiente, como una segunda nave de la mezquita. Desde ella, y por la citada puerta, se accedía al espacio que correspondía a la sala de oración, también cubierta con tejas. Esta es de planta rectangular, con una longitud interior de 6,40 $\mathrm{m}$ y una anchura de $2,80 \mathrm{~m}$. En la parte central del muro sur, la qibla, el vano del mihrab está delimitado por dos bloques verticales de granito, a modo de jambas, estando la parte inferior en parte tallada en la roca. El mihrab tiene una forma semicircular, sobresaliendo al exterior.

Dadas las pequeñas dimensiones de esta mezquita, no cabe duda de que se trata de un lugar de culto secundario, un oratorio, quizás asociado al barrio en el que se encuentra, y tal vez fruto de una fundación piadosa como solía ser frecuente en el mundo andalusí. En cuanto a su cronología, dadas sus toscas características constructivas - un zócalo de piedras muy irregulares recrecido con muros de tapial- todo parece indicar que se debió de levantar en los primeros momentos de ocupación de la ciudad, posiblemente en el siglo $X$.

La otra mezquita, de mayores dimensiones y de mejor calidad constructiva, se encuentra dentro del complejo de la alcazaba, en el espacio frente al recinto principal que anteriormente pudo haber estado ocupado por una barbacana. Su sorprendente hallazgo se produjo cuando se desescombró toda esa zona. Se compone de tres partes: un pequeño zaguán, un patio para las abluciones y la sala de oración. Todo el conjunto, de forma ligeramente trapezoidal, tiene una longitud máxima de 20 m y su anchura aumenta desde los $7 \mathrm{~m}$ de su lado este hasta 
los 10 de su lado oeste. Su superficie total es aproximadamente de unos $130 \mathrm{~m}^{2}$.

El acceso a la misma se hacía por una puerta ubicada en su extremo noroeste, que se abre al pasillo en rampa que asciende hacia la puerta de entrada al recinto principal de la alcazaba. Pasada la puerta de la mezquita, se entraba en una pequeña pieza, a modo de zaguán o de vestíbulo, que posiblemente servía para que los fieles se descalzasen. Desde ella, se podía acceder directamente a la sala de oración por una puerta que se encuentra a mano izquierda. Este vano se podía cerrar con una puerta de dos hojas, como se puede comprobar por las huellas de las quicialeras que se han conservado. También, antes de entrar en la sala de oración, se podía acceder a otro espacio, por una puerta que se encuentra frente a la de entrada -que también se podía cerrar-, en el que se conserva parte de unas piletas, hechas con cal a nivel del suelo, y que servirían para realizar las imprescindibles abluciones. Desaguaban al exterior por un canalillo que se abre en el muro oeste. Desde este recinto, que se encontraba a cielo abierto actuando como patio, se podía pasar directamente a la sala de oración ya que estaba comunicado con tres de sus naves longitudinales.

La sala principal o de oración, estaba constituida por 4 naves longitudinales y otras tantas transversales, configurando 16 espacios interiores, separados por columnas de granito en la parte central -de las que se han conservado algunos fustes- y pilares adosados a los muros norte y sur (en éste en huecos abiertos en el tapial). Estas columnas y pilares sostenían arcos de herradura fabricados en ladriIlo, que presentaban un falso dovelaje pintado en blanco y rojo. El mihrab, de planta semicircular, se encuentra tallado en el tapial del muro sur, y originariamente habría estado decorado interiormente con molduras fabricadas con cal. Es de señalar que no ocupa una posición central en la sala de oración, aunque sí con respecto a la longitud de todo el muro de la qibla, si se le añade el espacio ocupado por el patio de las abluciones. Todo el interior de la mezquita debió de estar recubierto de cal y en algunas zonas -como en los zócalos- pudo haber presentado alguna decoración pintada en color rojizo. El suelo también era de cal. En el muro este se conservan los restos de una puerta tapiada que, originariamente, pudo haber funcionado como entrada directa a la sala de oración por aquella parte.

Cuando se excavó todo el conjunto y se limpió el suelo de la mezquita se pudo comprobar que en algunas zonas estaba cortado por lo que parecían ser fosas que, aparentemente, podían corresponder a enterramientos. Una vez excavadas se constató que, efectivamente, se trataba de tumbas. Se localizaron un total de siete enterramientos que, por las características de las fosas, la orientación y la colocación de los cuerpos, parecen corresponder a un ritual cristiano. Pertenecerían, por consiguiente, a un momento de ocupación cristiana de la ciudad -o solamente de la alcazabaen el que la mezquita se habría convertido en templo cristiano, y de ahí la presencia de estos enterramientos en su interior. Lo que no se puede precisar es a qué momento cronológico pueden corresponder; si a una fase inmediatamente posterior a la ocupación cristiana de la ciudad o a una fase ya algo posterior de un intento de repoblación.

Muy posiblemente se trate de un edificio levantado en el siglo Xl, para atender a las necesidades de culto de la población en aumento que se concentraría en la alcazaba. Momento en el que, aparte de otras remodelaciones, también se construiría el barrio de la parte oeste para acoger a los nuevos contingentes militares.

\section{HIPÓTESIS SOBRE LA FUNDACIÓN DE VASCOS}

Sin embargo, contra lo que pudiera pensarse a la vista de este impresionante yacimiento que tanto ha llamado la atención de los arqueólogos y de los historiadores que se han acercado al mismo, son muchos los interrogantes que todavía sobre él se ciernen. En efecto, a diferencia de otros casos conocidos, y de una manera un tanto sorprendente, las fuentes documentales escritas islámicas apenas aportan 
datos acerca del momento de fundación y abandono de esta ciudad, de su función y sentido originarios, de las gentes que la habitaron y hasta de su auténtico nombre. Todo lo cual ha supuesto que hayan sido muchas las hipótesis que a este respecto se han elaborado, algunas no exentas de cierta dosis de inverosimilitud.

Por lo que respecta al momento cronológico de su fundación y los motivos que llevaron a levantarla precisamente en aquel lugar, ante la falta de referencias documentales precisas son varias las interpretaciones o hipótesis que se pueden señalar a este respecto. Es posible que la fundación de Vascos se hubiese llevado a cabo durante el gobierno de Abd alRahmán III. No obstante, no conviene olvidarse de esa ciudad de nombre desconocido, señalada en algunos textos, que se construyó o reconstruyó en la frontera de Toledo durante el mandato de su sucesor al-Hakam II y de la que se conoce el nombre de su arquitecto (Ahmad b. Nasr b. Jalid). Es posible que Vascos, como madina, se fundase entre el año 930 y el 950 aproximadamente. En cualquier caso, lo que parece evidente es que se trata de una fundación omeya, con un sentido "oficial", asociada al poder cordobés, como parece transmitir, con un sentido simbólico, la calidad de la construcción de la muralla en algunos tramos.

Ahora bien, ¿cuales fueron los auténticos motivos que, desde Córdoba -donde se generaría la iniciativa-, impulsaron a los Omeyas a levantar una ciudad precisamente en aquel lugar aparentemente inhóspito? Desgraciadamente los desconocemos y, como en otros planteamientos, aquí tenemos también que entrar en el campo de las hipótesis, no siempre fáciles de demostrar. A este respecto consideramos que, para los intereses omeyas, podían haber entrado en juego tres posibles supuestos, determinantes en la elección del lugar, que se combinarían entre sí: uno de carácter estratégico, otro político y otro económico.

El motivo estratégico habría que ponerlo en relación con la necesidad defensiva de la línea del Tajo -en especial en su curso medio-, política que inició el propio Abd al-Rahmán III y luego continuaron sus sucesores, con la forti- ficación de diversos núcleos a lo largo del río. Se trataba, por consiguiente, de controlar los principales pasos naturales hacia los cuales se habría de orientar cualquier incursión cristiana como ya había ocurrido en los años anteriores. En las inmediaciones de Vascos existía un vado en el Tajo, al que desde antiguo confluían diversas vías de comunicación. Se trataba, por tanto, de un punto estratégico del que se hacía absolutamente necesario su control. En principio, parecería que lo más oportuno hubiese sido haber levantado la ciudad junto al mismo. Sin embargo, ello no se hizo así, y la ciudad -por causas que desconocemos- se construyó algo más alejada, aunque no a mucha distancia, en un paraje retirado. Para el control del vado se levantarían sendas fortalezas, a ambos lados del Tajo, de las que no se han conservado sus restos, aunque la toponimia actual, de clara raíz árabe, nos está señalando su existencia en las localidades toledanas de Alcolea y Azután (Bury al-Sultan). Estas fortalezas dependerían, evidentemente de Vascos, donde se organizaría su sistema de vigilancia. De tal manera que, desde este enclave, a pesar de su relativo alejamiento, se procedía al control de este importante paso, y de ahí la función estratégica que estaba desempeñando en el dispositivo fronterizo de al-Andalus, en esta zona del Tajo, y que bien pudo haber sido uno de los motivos que, junto a otros, coadyuvaron a su fundación.

El supuesto político que podría haber incidido en la fundación de Vascos vendría señalado por la situación de inestabilidad que en los primeros años del siglo $X$ todavía continuaba presentando esta zona. En ella, desde pronto, se habían establecido gentes de origen bereber, pertenecientes a diversas tribus, entre las cuales la de Nafza debió de tener un mayor protagonismo. En general, los bereberes de al-Andalus no aceptaron de buen grado la imposición del poder omeya y se sublevaron con frecuencia. El propio Abd al-Rahmán III, estando en Toledo tras haber conseguido su pacificación en el año 932, tuvo que enviar tropas a la zona de Talavera donde se habían vuelto a sublevar los Nafza. Ante aquella situación nos podemos plantear algunas preguntas aunque tienen, hoy por hoy, muy difícil respuesta ¿Pudo haber sido ese contexto de inestabilidad política el que propi- 
ciase la fundación de Vascos, como un enclave omeya desde el cual controlar una zona hostil a su autoridad? iFue fundada la ciudad con la finalidad de recoger en ella a los miembros de la tribu Nafza, los más rebeldes? Si este supuesto político hubiese existido, no cabe duda que también se combinaba con el supuesto estratégico ya señalado, pues era evidente que desde Vascos se controlaba una zona de implantación bereber, conflictiva, y un punto concreto significativo como era el vado del Tajo, del que era necesario prevenir su control ante posibles penetraciones cristianas.

En cuanto al supuesto económico, éste hay que ponerlo en relación con lo que tradicionalmente se ha venido señalando sobre Vascos: que fue un centro metalúrgico de cierta envergadura, en el que se trabajaban metales -especialmente preciosos- procedentes de las minas de los cercanos Montes de Toledo. Es cierto que en los alrededores de Vascos existieron minas abundantes y que las excavaciones nos han proporcionado algunos elementos que nos indican una cierta actividad metalúrgica en el lugar: escorias, martillos mineros, moldes, etc. Sin embargo, hasta el presente, no son lo suficientemente significativos como para considerar que sean el reflejo de una actividad de cierta envergadura y menos relacionada con el trabajo de metales preciosos. Más bien parecen relacionados con una explotación de hierro. No obstante, no descartamos que el lugar haya podido estar asociado, desde muy antiguo, con actividades minero-metalúrgicas proseguidas en etapas sucesivas. Con lo cual, en aquel lugar, en un punto que hoy desconocemos, se pudo haber desarrollado una infraestructura metalúrgica de cierta envergadura, que, en tal caso, los musulmanes no hicieron nada más que aprovecharla y continuarla. Lo único que éstos, en vez de mantenerla en un contexto reducido, la ampliarían integrándola dentro de una ciudad para así mejor controlar la producción, máxime si la zona era conflictiva. En tal caso, la obtención de hierro habría sido uno de los motivos que llevaron a los Omeyas a fundar Vascos en un enclave que ya contaba con una tradición minero-metalúrgica. Ese metal se podía llevar a Córdoba por la vía que pasaba por las inmediaciones.
Estos son los tres supuestos que, con la debida cautela, consideramos como más razonables para explicar las causas del origen de Vascos. Resulta imposible saber si fue solamente uno de ellos -y cuál- el único prioritario. Lo más probable es que fuese una combinación de todos ellos - unidos tal vez a otros que se nos escapan- lo que determinó a los Omeyas a fundar precisamente allí la ciudad: el control de una producción metalúrgica que se podía fácilmente encauzar hacia Córdoba por una vía cercana; el control de un territorio no siempre sumiso al poder omeya y el control de un paso natural del Tajo, cada vez más necesitado de vigilancia ante la creciente presión cristiana. Mientras la ciudad desempeñase estas supuestas funciones que estaban en su origen, podía pervivir; pero si las circunstancias cambiaban, la ciudad podía dejar de tener sentido $y$, por tanto, desaparecer, como de hecho ocurrió.

En cuanto al nombre originario de Vascos, la tendencia más generalizada entre algunos arabistas, desde que don Félix Hernández lo señalara por primera vez, es a identificar este enclave -a pesar de la acusada diferencia lingüística de ambos nombres- con la ciudad de Nafza, principal centro de asentamiento de la tribu bereber del mismo nombre a la que ya nos hemos referido por su actitud levantisca frente a los Omeyas.

En un texto de Ibn Galib que publicó Joaquín Vallvé se señala que, la cercana ciudad de Talavera (de la Reina) tenía tres distritos, uno de los cuales era el de Basak, que, por la semejanza del nombre, se tiende a identificar con Vascos. De ser esto cierto, lo cual es muy factible dada la proximidad de Vascos a Talavera, tendríamos la primera referencia documental sobre Vascos, aunque no como ciudad sino como distrito de otra; no obstante, cabe suponer que el distrito llevaría el mismo nombre que la ciudad.

De ser así, habría, por tanto, que desechar su identificación con Nafza. No obstante, de cara a conjugar ambos topónimos, cabría establecer la siguiente hipótesis: el nombre de la ciudad fue Nafza y el del distrito Vascos (Basak). Una vez que se despobló la ciudad, su nombre ori- 
ginario cayó en desuso hasta el extremo que se olvidó, pero no así el de su territorio que terminó por quedar vinculado a la ciudad abandonada, a la que terminaría por dar su nombre actual. Sería deseable que, en el futuro, algún hallazgo epigráfico nos pudiese aporte algún dato definitivo para resolver este dilema.

\section{SECUENCIA CRONOLÓGICA}

Ante la sorprendente falta de referencias documentales precisas sobre Vascos y para intentar concretar algunos aspectos con un mayor rigor histórico-arqueológico, se hacía preciso realizar excavaciones arqueológicas en el lugar. Éstas, con el objetivo de resolver algunos de los enigmas que se ciernen sobre el yacimiento, a la par que procurar conseguir una gradual puesta en valor del mismo, se iniciaron, bajo nuestra dirección, en el año 1975, subvencionadas hasta el año 1983 por el Ministerio de Cultura y, desde entonces, por la Consejería de Educación y Cultura de la Junta de Comunidades de Castilla-La Mancha.

Al comenzar por primera vez los trabajos arqueológicos el planteamiento fue de excavar, en sucesivas campañas, en distintas zonas del interior de la ciudad, para comprobar la secuencia estratigráfica de cada una de ellas y poder así establecer la existencia de posibles elementos diferenciadores entre las distintas zonas excavadas, a la par que se obtendrían una serie de resultados que podrían proporcionar los primeros elementos fiables sobre la ciudad -tales como los momentos iniciales y finales de actividad en el yacimiento-, los cuales, a su vez, servirían de punto de referencia a la hora de planificar los trabajos a realizar en el futuro. Además, también interesaba conocer otros aspectos de interés tales como sus características urbanísticas, la organización espacial de sus viviendas, la calidad y funcionalidad de los diversos objetos conservados, etc., es decir, el sistema de vida de sus habitantes así como las actividades a las que se pudieron haber dedicado.

También se ha excavado en algunas zonas del exterior, en espacios más concretos, que podían presentar un especial interés arqueo- lógico por los restos visibles en superficie (cementerios, baños, tenerías). Hasta el momento, las excavaciones se han realizado en ocho puntos diferentes: cuatro en el interior $y$ tres en el exterior de la ciudad, más aparte el conjunto de la alcazaba que se ha excavado en su totalidad.

Las excavaciones no han proporcionado elementos muy precisos de datación que nos pudiesen servir para encuadrar cronológicamente, con cierta exactitud, los límites de presencia humana en el lugar. No obstante, teniendo en cuenta las características de los materiales aparecidos y de los restos arquitectónicos exhumados, se puede establecer la siguiente secuencia cronológica, diferenciada en fases, al menos provisionalmente, mientras futuros hallazgos no la rectifiquen:

\section{Fase preislámica:}

- Época del Bronce: en el cerro que ocupa la alcazaba está atestiguada la presencia de un poblado en época del Bronce. Han sido bastante los materiales encontrados, algunos de ellos in-situ, correspondientes a esa época. Algunos son de cierta calidad, por lo que se podría señalar que el asentamiento debió de ser de cierta importancia.

- Época romana: los hallazgos numismáticos parecen indicarnos que, en esta época, al menos desde el siglo I d.C. y hasta el siglo IV se constata la existencia de un poblamiento, muy posiblemente asociado a un enclave de carácter metalúrgico, donde se trabajarían los minerales procedentes de las minas cercanas. Las abundantes escorias que se encuentran por todo el yacimiento, tal vez sean un reflejo de esta actividad. El material cerámico correspondiente a esta época es, sin embargo, muy escaso -exiguos fragmentos de terra sigillata y de tégulas-, lo cual parece indicar que la población sería también muy reducida. Este material aparece disperso por todo el interior de la ciudad, pues en todas las zonas excavadas siempre se ha encontrado algo, aunque descontextualizado. Por ello, no podemos precisar en qué zona concreta podría haber estado con- 
centrado este poblamiento en época romana. No parece que estuviese en el cerro de la alcazaba, como se ha comprobado en las excavaciones. Es de señalar que también han aparecido varias aras -alguna conservando restos de una inscripción-, y la basa de una columna de mármol, lo cual nos puede estar indicando la existencia de un lugar de culto cercano.

- Época visigoda: las excavaciones han proporcionado algunas hebillas de cinturón que parecen corresponder a esta época. Además, en uno de los muros de la mezquita que se localizó y excavó en la parte exterior de la alcazaba, se encontró, reutilizado, la mitad de un tenante de altar también de época visigoda, con sus cuatro caras talladas. Este hallazgo es muy significativo, pues nos permite corroborar lo que, a falta de elementos ciertos intuíamos: la continuidad y presencia de un poblamiento en el lugar en el momento de la aparición de los musulmanes. Cabe pensar que esta pieza no puede proceder de muy lejos, por lo que nos estaría señalando la existencia de una iglesia cercana levantada en aquella época. Al haberse encontrado en la zona de la alcazaba podría pensarse que allí se pudo haber levantado esa supuesta iglesia y que también allí pudo haberse concentrado un poblamiento en época visigoda, que tal vez fuese una continuación del mismo que pudo haber estado establecido ya en época romana. Sin embargo, las excavaciones que se han realizado en la alcazaba no permiten confirmar este supuesto ante la falta de hallazgos precisos, por lo que cabe pensar que la zona de asentamiento se encuentra en otro lugar.

\section{Fase islámica:}

- Etapa emiral: a esa población ya establecida de antiguo se pudieron añadir algunos elementos musulmanes llegados a la Península en el siglo VIII, que muy probablemente serían de origen bereber. Aunque todavía habrá de ser confirmado, consideramos que en época emiral, en el siglo IX, debió de haber un poblamiento asentado en el cerro de la alcazaba. No sabemos si formado por contingentes musulmanes o por una población hispanovisigoda islamizada, aunque una parte pudo haber continuado como cristiana. En cualquier caso, parece que esta población se protegió mediante una muralla, con lo cual, lo que se vino a constituir fue como un hisn, enclavado en lo alto del cerro. Parte de esta muralla -que es de técnica constructiva muy sencilla, simplemente de mampuesto- se ha conservado, pues se encuentra reutilizada en el interior de la muralla principal que posteriormente se levantó en la alcazaba. Algunos tramos de ésta se han caído y han dejado al descubierto la muralla anterior.

Para intentar explicar este fenómeno de fortificación del lugar, se podría aplicar el mismo proceso que se viene señalando en otras zonas de al-Andalus. Por una parte, la reacción de muchas poblaciones, que se negaron a asumir y cumplir las exigencias tributarias cuando se instauró el poder omeya, por lo cual abandonaron sus primitivos asentamientos estableciéndose en lugares apartados, de difícil acceso, como es el caso de Vascos, ubicado en un paraje aislado y un tanto escondido, ¿intencionadamente?

Por otra parte, habría que tener también en cuenta la situación que se produjo en alAndalus durante la segunda mitad del siglo $\mathrm{IX}$, la que algunos historiadores vienen denominando como la primera fitna y que corresponde a la crisis del Emirato. Debido a la situación de aguda inestabilidad política que entonces se produjo, y que se manifestó en las numerosas revueltas que abarcaron a la mayor parte del territorio andalusí, muchas poblaciones rurales se fortificaron, aprovechando la topografía de sus emplazamientos. Fueron muy numerosos los husun que entonces se levantaron en al-Andalus - de construcción muy sencilla-, unos a iniciativa de la propia población rural y otros bajo la tutela del mismo poder omeya, orientada a proteger a aquellas poblaciones fieles a su autoridad y evitarles la ingerencia y las exigencias de cualquier personaje sublevado en las inmediaciones. 
Es muy posible que en ese contexto haya que encuadrar la fortificación del cerro de la alcazaba, para proteger a la población que en aquellas circunstancias allí se estableció, procedente de algún punto que consideramos cercano. Sería entonces cuando se levantaría la muralla de mampostería, aunque no podamos saber si por iniciativa de los propios pobladores allí concentrados o del mismo poder omeya, con la intención de protegerlos pero también, evidentemente, de controlarlos. En cualquier caso, si estas premisas se cumpliesen para el caso de Vascos, y los argumentos expuestos consideramos que pueden ser aceptables, tendríamos el ejemplo de otro hisn -de superficie reducida-, y la confirmación de un asentamiento islámico ya en época emiral, aunque todo esto habrá de ser ratificado arqueológicamente.

- Etapa califal: la siguiente etapa correspondería a época califal, que sería en la que se levantaría la ciudad. Cuando Abd al-Ramán III llegó al poder, se encontró con un alAndalus desde hacía tiempo sublevado, al que tuvo poco a poco que pacificar. Para ello, entre otras medidas, mandó destruir muchos de los husun que se habían levantado en los años anteriores, pero otros, los que servían a sus intereses, los siguió conservando. Entre ellos, es posible que este de Vascos. Sin embargo, en este caso, se iba a producir un hecho significativo y es que a partir del hisn, y tal vez por los tres motivos anteriormente expuestos, se fundaría toda una ciudad. No sabemos en qué momento preciso, pero el hecho es que el poder omeya decidió levantar allí un enclave de entidad urbana.

Para ello, el punto de partida fue precisamente el cerro donde estaba ubicado el hisn, en el cual se levantó un nuevo recinto que iba a ser la imprescindible alcazaba de la nueva ciudad. Se amplió su superficie y, en parte, se aprovechó la anterior muralla de mampostería que quedó englobada dentro de la nueva, de mejor calidad constructiva, en la que se empleó sillería, más acorde con las pretensiones ideológicas de manifestación del poder omeya. Y, a partir de la alcazaba, una vez garantizado el suministro de agua para la futura población, se trazaría el perímetro que iba a ocupar la ciudad y se empezaría a levantar la muralla, con distintas cuadrillas trabajando al mismo tiempo en tramos diferentes. De esta manera, se podría decir que Vascos pasó de hisn a madina.

- Etapa de la segunda fitna: otro momento significativo para Vascos pudieron haber sido los años conflictivos, de crisis política generalizada en al-Andalus, que se vienen conociendo como la segunda fitna (finales del siglo $X$ y primer tercio del siglo XI), que terminaría con la dinastía omeya $y$, por ende, con el Califato cordobés. Es muy posible que la ciudad, que no en balde era un centro vinculado al poder omeya, hubiese sido escenario de conflictos violentos, que hubiesen conllevado destrucciones de edificios en su interior, como en algunas zonas excavadas se deja entrever, especialmente en la alcazaba que debió de resultar en gran parte destruida dado su significado político. Los muertos que en ella se produjeron, unos cincuenta, fueron enterrados en la misma alcazaba, en el nivel de destrucción que se originó, como han puesto de relieve las excavaciones.

- Época taifa: la siguiente y última fase de ocupación islámica correspondería al siglo XI, es decir, a la época de las taifas. Una vez superada la fitna se constituyó la taifa o reino de Toledo, en el cual Vascos quedó integrado, en su extremo más occidental, en una posición estratégica relevante. En efecto, este enclave adquirió entonces un doble carácter fronterizo, por lo que su significado militar quedó reforzado. Por una parte, siguió conservando el control del cercano vado del Tajo, en unos momentos en los que la presión cristiana en aquella zona comenzó a hacerse cada vez más insistente. Y, por otra, se convirtió en una avanzadilla frente al vecino y próximo reino de Badajoz, con el cual las relaciones con los toledanos nunca fueron muy cordiales. De ahí ese doble carácter fronterizo que entonces Vascos 
adquirió, y de ahí la importancia que el control de la plaza tenía para el reino de Toledo y para la dinastía de los Di I-Nun que lo gobernó, por su indudable valor estratégico en la nueva coyuntura política.

En esta época Vascos debió de llegar al máximo de su crecimiento demográfico, habiendo estado el interior de la madina posiblemente ocupado por completo, adosándose edificios a la muralla sobre espacios anteriormente despejados. Tras la superación de la fitna el lugar se volvería a repoblar y los edificios afectados por las destrucciones se reconstruyeron -como se ha observado arqueológicamente, sobre todo en la alcazaba-y se pudo haber producido incluso una cierta reurbanización de la ciudad en algunas zonas. Cabe pensar que, debido al reforzamiento de su carácter estratégico, la presencia de efectivos militares aumentaría, quedando entonces al mando de un gobernador nombrado por los reyes toledanos cuyos intereses tenía que defender. Por ello fue necesario ampliar el recinto principal de la alcazaba hacia su lado oriental, lo que supuso tener que establecer un nuevo acceso controlado por aquella parte.

Es posible que en el aquel contexto, Vascos, y en especial su alcazaba, hubiese adquirido un cierto carácter de ribat, al que acudiesen voluntarios musulmanes con el objetivo de defender -bajo los planteamientos de la guerra santa- aquel punto fronterizo de cualquier incursión cristiana que se pudiese producir. Para acoger a aquel numeroso contingente de soldados, se levantaría entonces el pequeño barrio fortificado, anejo a la alcazaba en su parte oeste, lo que también conllevó el reforzamiento del acceso a ésta por aquella parte con la construcción de un recinto previo. De igual manera, también a este momento correspondería la construcción de la mezquita levantada en la zona de la barbacana, de dimensiones amplias, para dar cabida a una tropa numerosa, que cabe suponer imbuida de un celo religioso-militar intenso y necesitado de un lugar de culto inmediato. Por su ubicación, en el complejo de la alcazaba, consideramos que esta mezquita estaría solamente para el uso exclusivo de los ocupantes de ésta.

Durante el tiempo que Vascos perteneció a la taifa de Toledo, aparte de su función estratégico-militar, es muy posible que en ella se hubiese seguido practicando la supuesta actividad minero-metalúrgica de etapas anteriores. En cualquier caso, lo que es indudable es que el enclave, por la posición en la que se encontraba, representó un especial significado para la dinastía de los Di I-Nun, por lo que no es sorprendente que procediesen a incrementar su población y a reforzar su carácter militar con la reconstrucción y ampliación del complejo de la alcazaba.

\section{Fase cristiana:}

- Reinado de Alfonso VI: desconocemos el momento exacto en que se produjo el paso de Vascos a poder cristiano. Siempre habíamos considerado que tuvo que coincidir con el momento en que el rey castellanoleonés Alfonso VI ocupó la ciudad de Toledo, y su taifa, en el año 1085. Afortunadamente, estas suposiciones han quedado confirmadas por el hallazgo, en las excavaciones de la alcazaba, de varias monedas correspondientes al reinado de este monarca. No hay duda, por consiguiente, que entonces la ciudad ya estaba en manos cristianas y que esas monedas habrían pertenecido a los soldados que allí se establecieron. Ahora bien, ¿cuando se produjo el acontecimiento? ifue el año 1085 o unos años antes?

Planteamos estos interrogantes porque, en el año 1080, el rey toledano al-Qadir, para hacer frente a los graves problemas políticos internos por los que estaba atravesando, buscó la ayuda de Alfonso VI. Éste se comprometió a prestársela y, a cambio, recibió algunas fortalezas, entre ellas la de Canturias, que se encontraba junto al Tajo, entre Vascos y Talavera. Esta circunstancia nos lleva a considerar que Alfonso $\mathrm{VI}$ ya controlaba esta zona del río y que muy bien pudo también entonces haber controlado Vascos hacia 
el año 1080. En cualquier caso, la cercana presencia de tropas cristianas pudo haber conllevado un gradual abandono de la ciudad por muchos de sus habitantes, lo cual habría facilitado su ocupación por parte de aquél. Lo que es evidente, es que Vascos, al margen de la fecha precisa, fue ocupada durante el reinado de Alfonso $\mathrm{VI}$, aunque no sepamos si con la intervención directa y personal de éste.

Lo que sí parece constatado por las excavaciones realizadas es que no se debió de producir una ocupación violenta de la ciudad, que se hubiese materializado en destrucciones y en incendios de los edificios. Por lo cual cabe pensar que, o la ciudad capituló y se entregó sin resistencia, o que sus habitantes musulmanes ya la habían abandonado cuando se produjo su ocupación por las tropas cristianas. Éstas se establecerían, evidentemente, en la alcazaba y muy posiblemente señoreaban sobre una ciudad completamente despoblada. No obstante, desde aquella posición se podía controlar también todo el territorio circundante y las principales vías de comunicación. En cualquier caso, en aquellas circunstancias no parecía todavía muy propicio iniciar una repoblación cristiana dada la cercanía de los musulmanes. Es posible que, mientras se mantuvo esta presencia militar en la alcazaba la mezquita que allí se había levantado se hubiese adaptado al culto cristiano y se hubiese convertido, por tanto, en una iglesia, como parecen confirmar los enterramientos que en ella se excavaron.

No obstante, esta presencia cristiana pudo haber durado poco tiempo, por la inmediata llegada de los almorávides a la Península. Éstos, en varias ocasiones a finales del siglo $\mathrm{XI}$, atacaron Talavera, $\mathrm{y}$ en sus incursiones tuvieron que pasar por las inmediaciones de Vascos. Cabe suponer que entonces el enclave ya no contaría con una presencia cristiana y se encontraría abandonado. No parece tampoco, al menos no se ha constatado arqueológicamente, que pudo haber estado en poder de los almorávides. De haber sido así, su presencia hubiese sido efímera -una pequeña tropa acantonada en la alcazaba- y no ha dejado huella perceptible.

Una vez pasado el peligro almorávide, no sabemos si Vascos volvió a contar de nuevo con una presencia militar cristiana -que tampoco sería muy duradera- o si ya quedó definitivamente abandonado, como parece lo más probable. Pretender repoblar el lugar presentaría muchas dificultades, dado su emplazamiento, en una zona un tanto aislada y, por tanto, poco atractiva. Además, es posible que su sistema de abastecimiento de agua hubiese quedado inutilizado, al igual que la supuesta infraestructura metalúrgica que pudo haber existido en la ciudad. En tales circunstancias era muy difícil que una población se decidiese a establecerse en el lugar, por muy protegida que pudiese sentirse al amparo de la muralla que seguía en pie. Además, no hay que olvidar que se trataba de un espacio urbano relativamente extenso, con lo que su completa ocupación se hacía todavía más dificultosa ya que se requerían numerosos repobladores.

Por todo lo cual, al dejar de tener, en el nuevo contexto político cristiano el sentido originario que había tenido para los musulmanes, Vascos, que ya no se encontraba en una zona de frontera ni tenía que defender especialmente nada, quedó definitivamente abandonado. Repobladores cristianos sí acudieron a la zona, pero prefirieron establecerse en las vegas del Tajo, más aptas para los cultivos agrícolas, y no en esta zona aislada, en la que los recursos económicos solamente se podían sustentar en una actividad pastoril.

Toda esta secuencia cronológica se ha podido elaborar gracias a un análisis interpretativo de los resultados arqueológicos proporcionados por los trabajos que se han venido realizando en el yacimiento y que, aparte de su provisionalidad, suponen un aporte significativo dados los escasos datos que anteriormente se tenían sobre el mismo. Esperamos que las excavaciones que se realicen en el futuro, nos deparen nuevos elementos que nos permitan confirmar o modificar los planteamientos aquí 
señalados, y así poder ir, poco a poco, desvelando algunas de las muchas incógnitas que todavía se ciernen sobre esta misteriosa ciudad.

\section{BIBLIOGRAFÍA}

En esta relación bibliográfica presentamos los estudios que se han publicado desde que comenzamos los trabajos arqueológicos en Vascos. Anteriormente fueron muy pocas las referencias bibliográficas sobre el lugar.

\section{Trabajos realizados por nosotros:}

"La ciudad hispanomusulmana de Vascos", en Historia 16, $n^{\circ} 29$, p. 66-72.

"Avance de las excavaciones realizadas en la ciudad hispanomusulmana de Vascos (Navalmoralejo, Toledo)", en Actas del XV Congreso Nacional de Arqueología, p. | | 6 | - | 172.

"Excavaciones arqueológicas en la ciudad hispanomusulmana de Vascos (Navalmoralejo, Toledo). Campañas 1975-1978", en Noticiario Arqueológico Hispánico, n 7 , 1979, p. 247-329.

"Vascos, une ville berbère en Espagne?", en Bulletin d'Archéologie Marocaine, XIV, I98I-82, p. 33I-345.

"Ciudad hispanomusulmana de Vascos (Navalmoralejo, Toledo). Campañas 1979-1980", en Noticiario Arqueológico Hispánico, n 16, 1983, p. 289-380.

"La cerámica hispanomusulmana decorada de Vascos (Toledo)", en Homenaje al Prof. Martín Almagro Basch, IV, 1983, p. 107-|| 5.

"Los baños árabes de Vascos (Navalmoralejo, Toledo)", en Noticiario Arqueológico Hispánico, n² 28, 1986, p. 193-242.

"Tipología de la cerámica hispanomusulmana de Vascos (Toledo)", en Segundo Coloquio Internacional de Cerámica Medieval en el Mediterráneo Occidental, 1986, p. II3-125.

"La cerámica común de Vascos. Estudio estadístico", en Actas del II Congreso de Arqueología Medieval Española, II, 1987, p. 7||-7|8.

"Una ciudad de fundación musulmana: Vascos", en Castrum (Guerre, fortification et habitat dans le monde méditerranéen au Moyen Age), n³ 3, 1988, p. 163-172.

"La vivienda en la ciudad hispanomusulmana de Vascos (Toledo). Estudio arqueológico", en La casa hispano-musulmana. Aportaciones de la Arqueología, Granada, 1990, p. 147-162.

"Excavaciones de Vascos: resultados y planificación", en Actas del Primer Congreso de Arqueología de la Provincia de Toledo, Toledo, 1990, p. 433-457.
"Los cementerios de la ciudad hispanomusulmana de Vascos", en Actas del III Congreso de Arqueología Medieval Española, II, 1992, p. 39|-396.

Ciudad hispanomusulmana Vascos (Navalmoralejo, Toledo). Campañas 1983-1988, Servicio de Publicaciones de la Junta de Comunidades de Castilla-La Mancha, Toledo, 1994.

"Unas tenerías excavadas en la ciudad hispanomusulmana de Vascos (Toledo)", en Arqueología y Territorio Medieval, 3, 1996, p.149-165.

"Los trabajos arqueológicos en la ciudad hispanomusulmana de Vascos (Navalmoralejo, Toledo)", en Castellum, 2, 1996, p. 123-130.

"Aspectos de la vida cotidiana en la ciudad hispanomusulmana de Vascos a través de los hallazgos arqueológicos", en Toletum, 36, 1998, p. 9-43.

"Nuevas formas cerámicas de Vascos", en Arqueología y Territorio Medieval, 6, 1999, p. 19|-206.

Vascos: la vida cotidiana en una ciudad fronteriza de alAndalus, Servicio de Publicaciones de la Consejería de Educación y Cultura de la Junta de Comunidades de Castilla-La Mancha, Toledo, 1999 (catálogo de la exposición celebrada en Toledo en el mes de junio de 1999).

La ciudad hispanomusulmana de Vascos. Nalvalmoralejo (Toledo), Toledo, 2000.

\section{Trabajos realizados en colaboración con Ger- mán Prieto Vázquez:}

"Los sistemas hidráulicos de la ciudad hispanomusulmana de Vascos" en I Coloquio de Historia y Medio Físico, I, Almería, 1989, p. 469-486.

"Una pequeña mezquita encontrada en Vascos (Navalmoralejo, Toledo)", en Cuadernos de la Alhambra, vol. 2930, 1993-1994, p. $21-38$.

\section{Trabajos de otros investigadores:}

COSIN CORRAL, Yolanda: "Un ejemplo de minería islámica: la ciudad hispanomusulmana de Vascos (Navalmoralejo, Toledo)", en Arqueología e Historia de la minería y metalurgia, Escuela Técnica Superior de Ingenieros de Minas, Madrid, 1996, 106-119.

COSIN CORRAL, Yolanda - GARCIA APARICIO, Constantino: "Minería y metalurgia en Vascos (Navalmoralejo, Toledo): ¿cambio tecnológico o continuidad material", en IV Congreso de Arqueología Medieval Española, 1994, III, $89 \mid-897$

COSIN CORRAL, Yolanda - GARCIA APARICIO, Constantino: "Alquerque, mancala y dados. Juegos musulmanes en la ciudad de Vascos", en Revista de Arqueología, 201, 1998, 38-47.

JUAN ARES, Jorge de: "La alcazaba de Vascos: aproximación a su evolución y características", en Entre el Califato y la Taifa: mil años el Cristo de la Luz, Toledo, 1999, 307-315. 

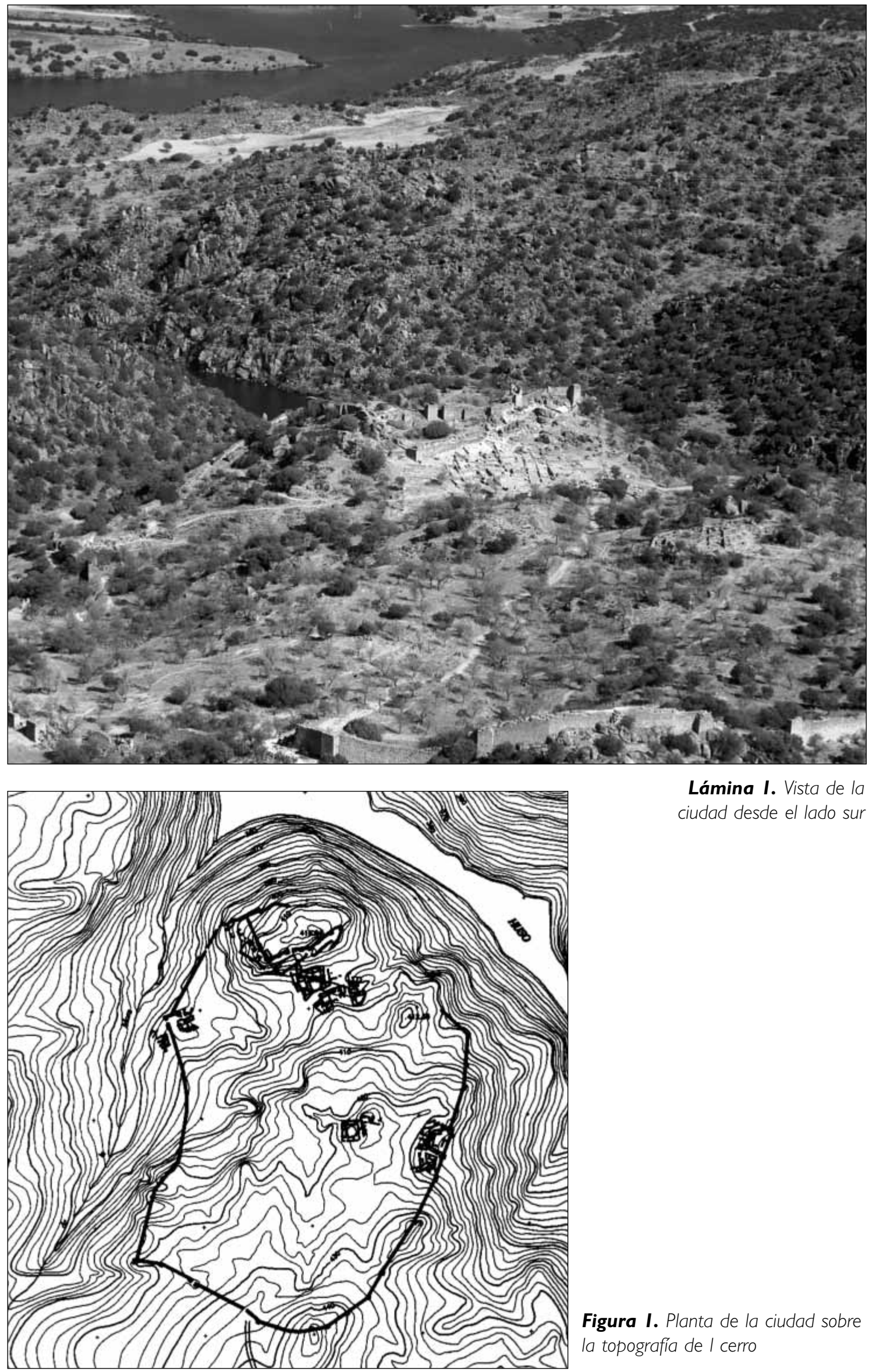

Lámina I. Vista de la ciudad desde el lado sur

Figura I. Planta de la ciudad sobre la topografía de I cerro 


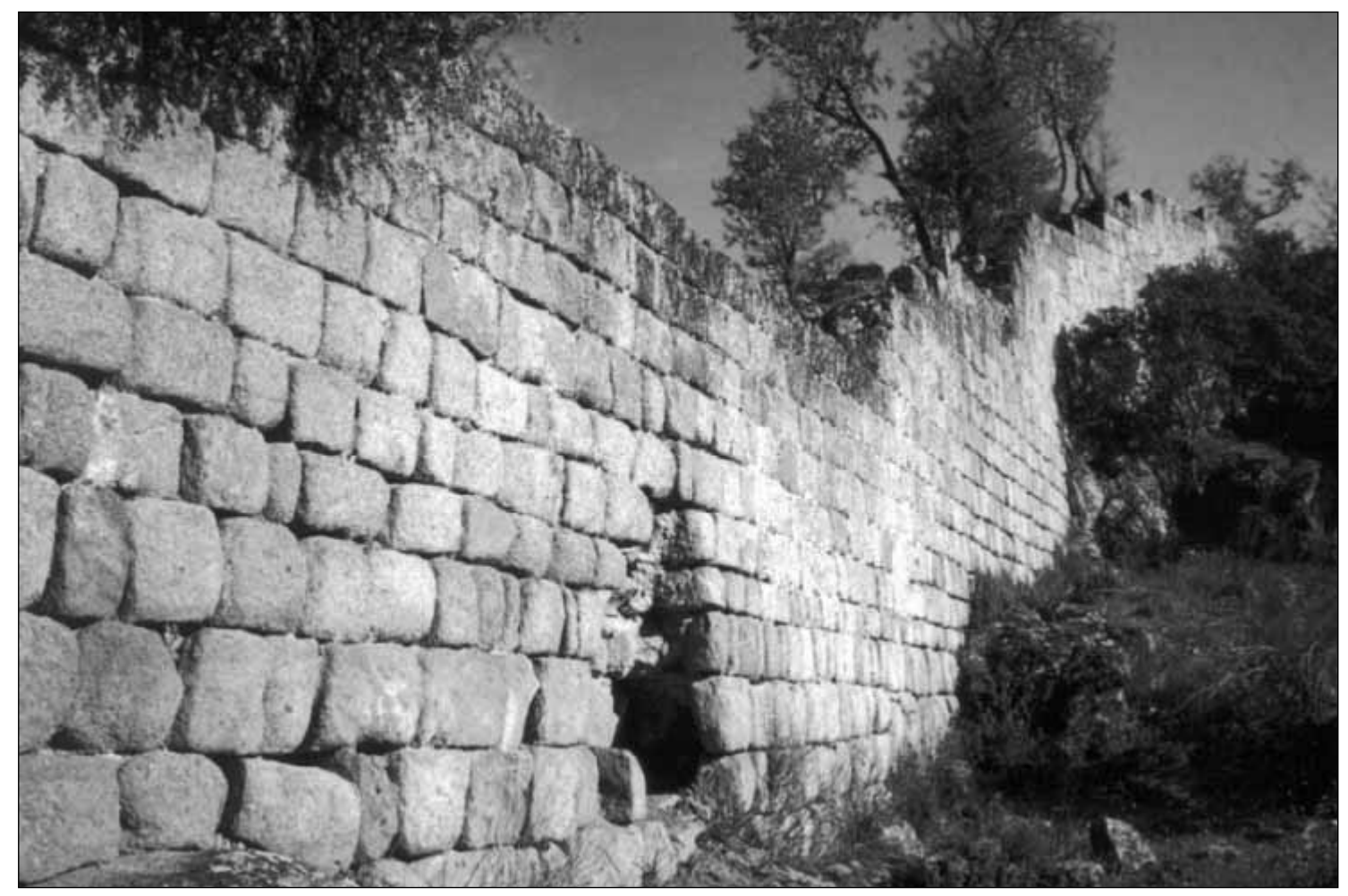

Lámina 2. Lienzo de muralla en el tramo oeste

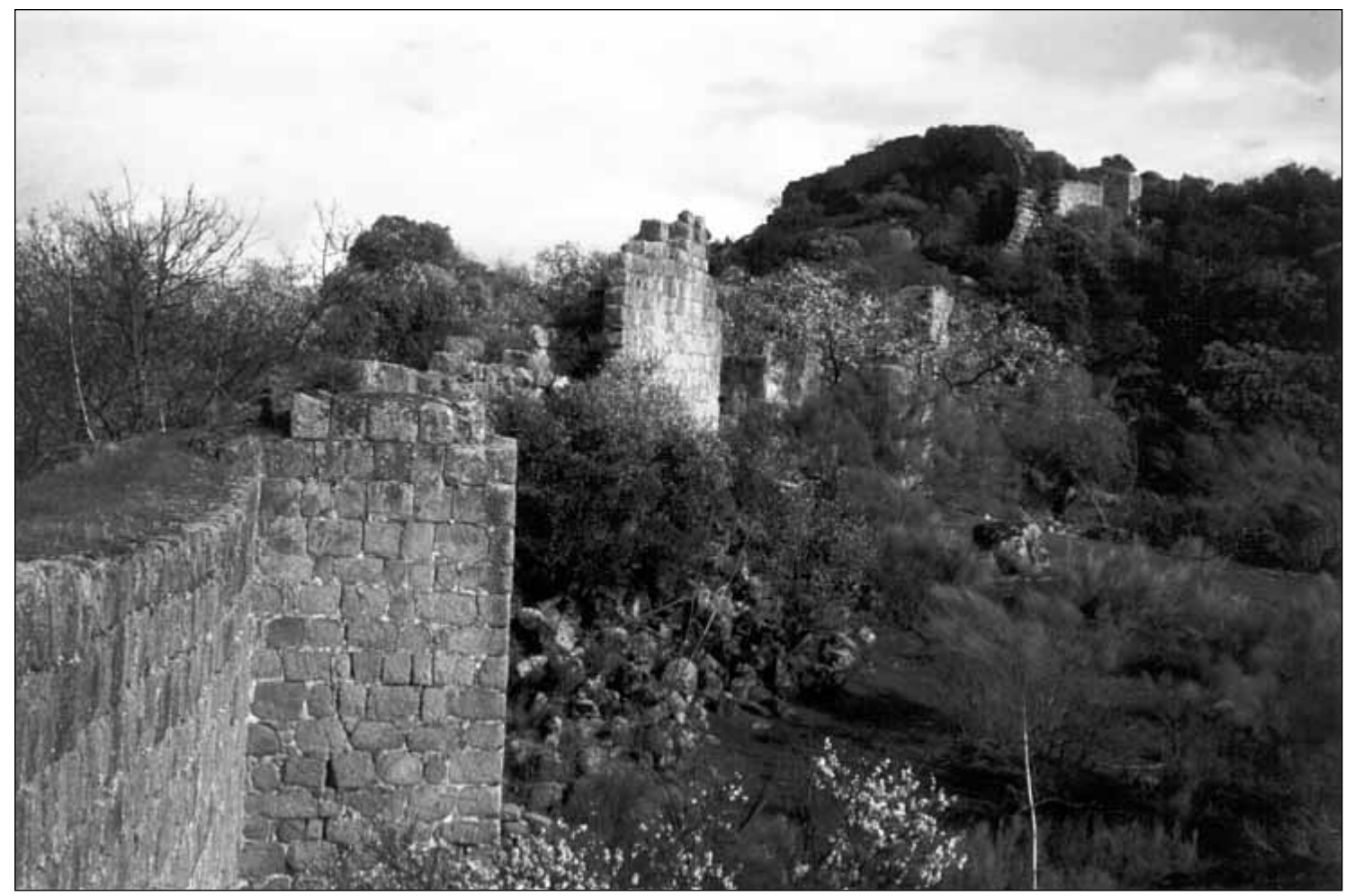

Lámina 3. Tramo de muralla en la zona sur 


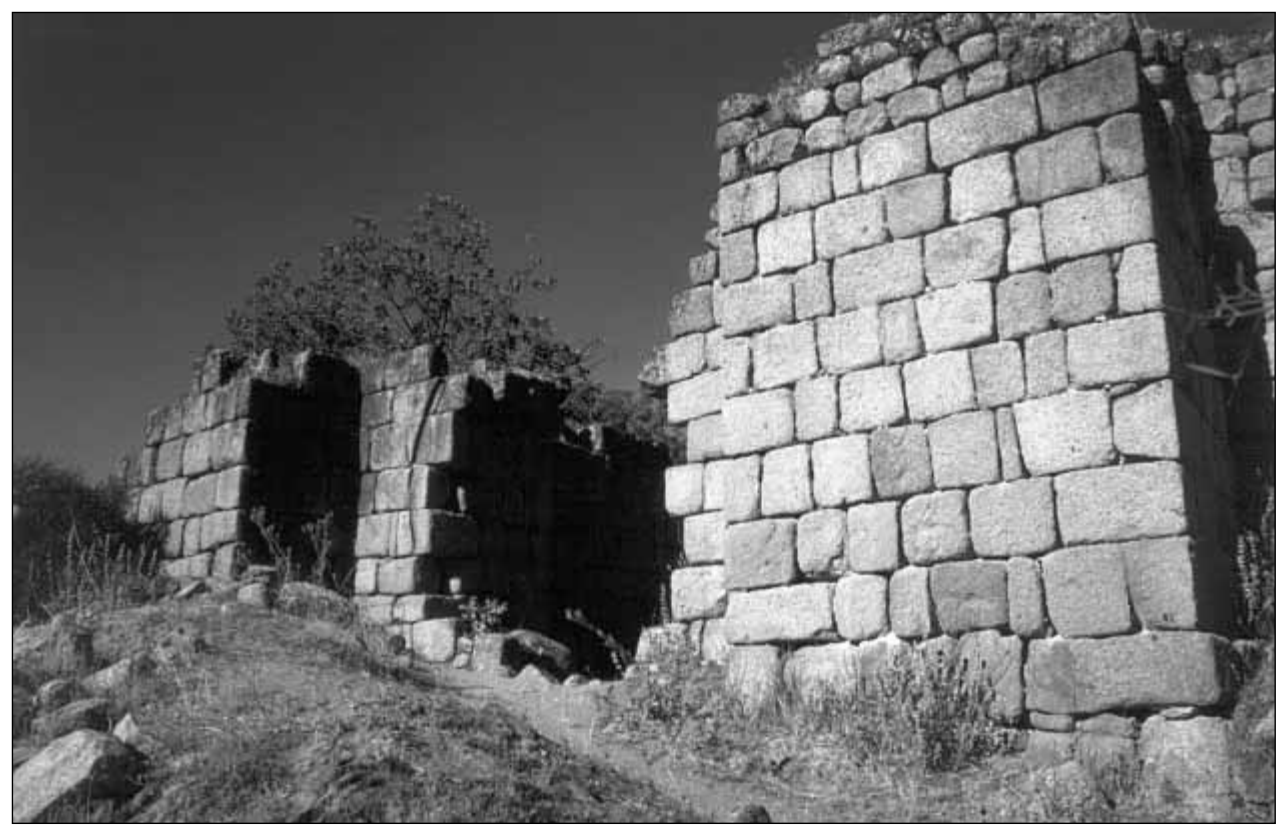

Lámina 4. Puerta oeste

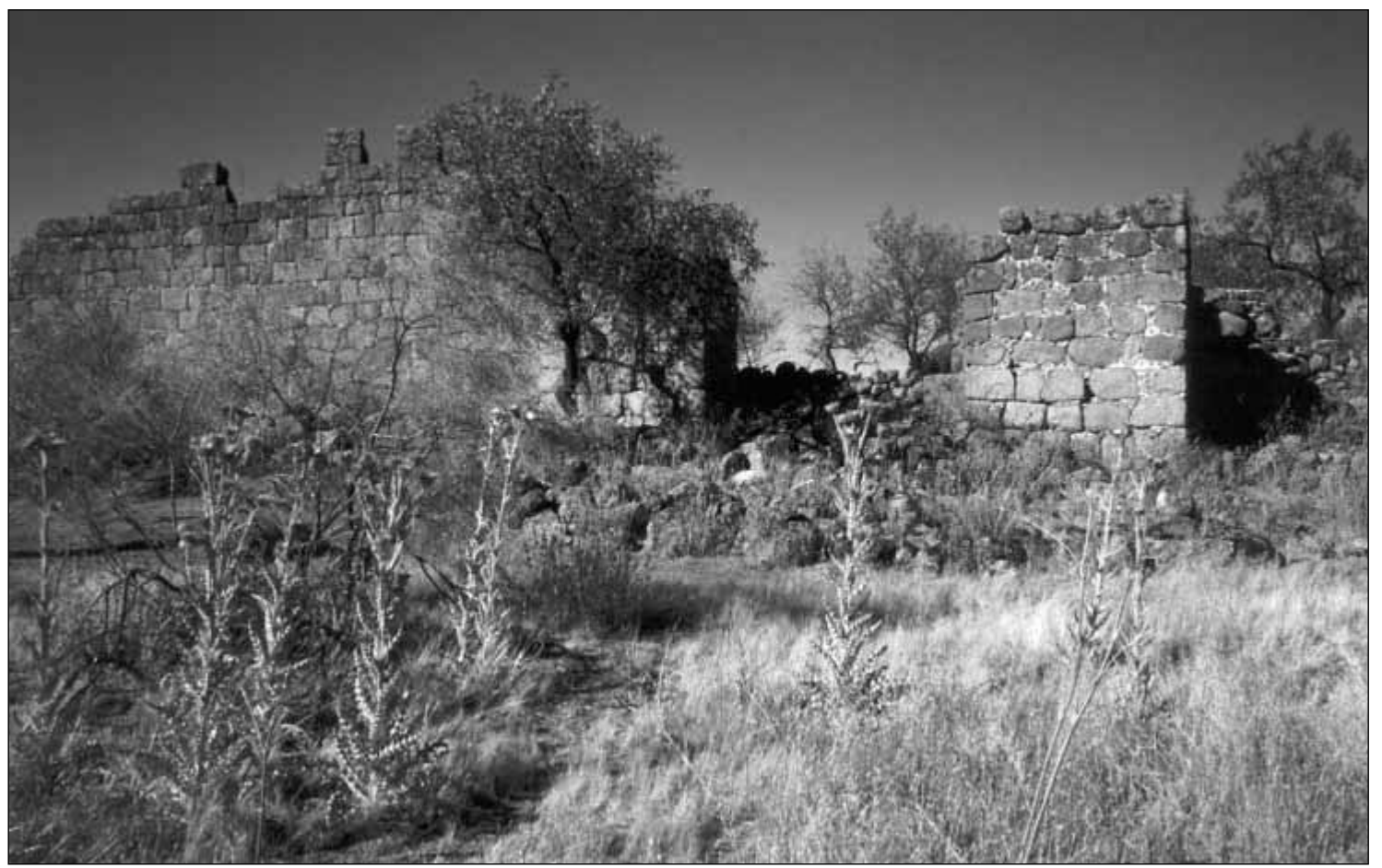

Lámina 5. Puerta sur 


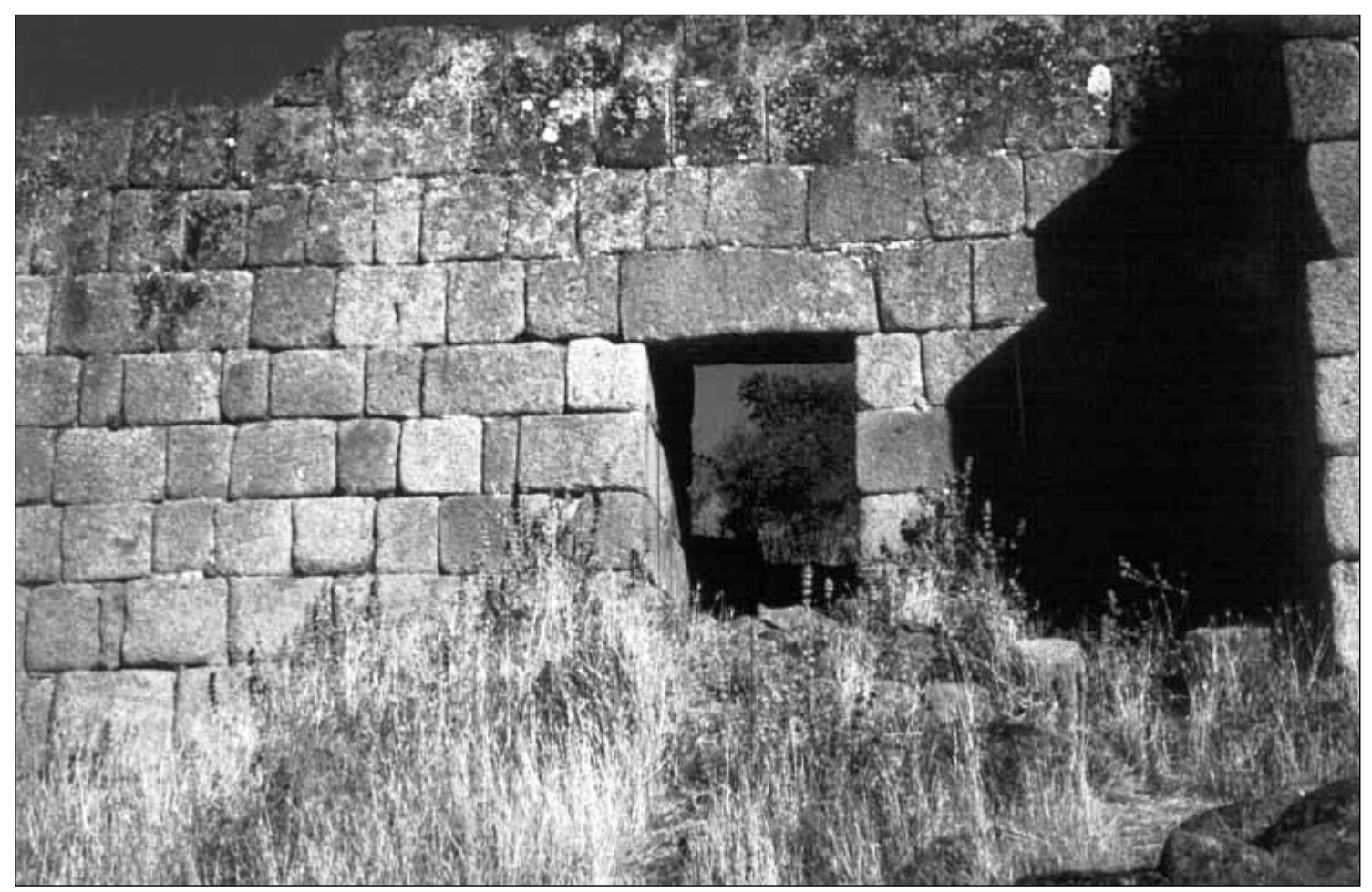

Lámina 6. Portillo de la zona oeste

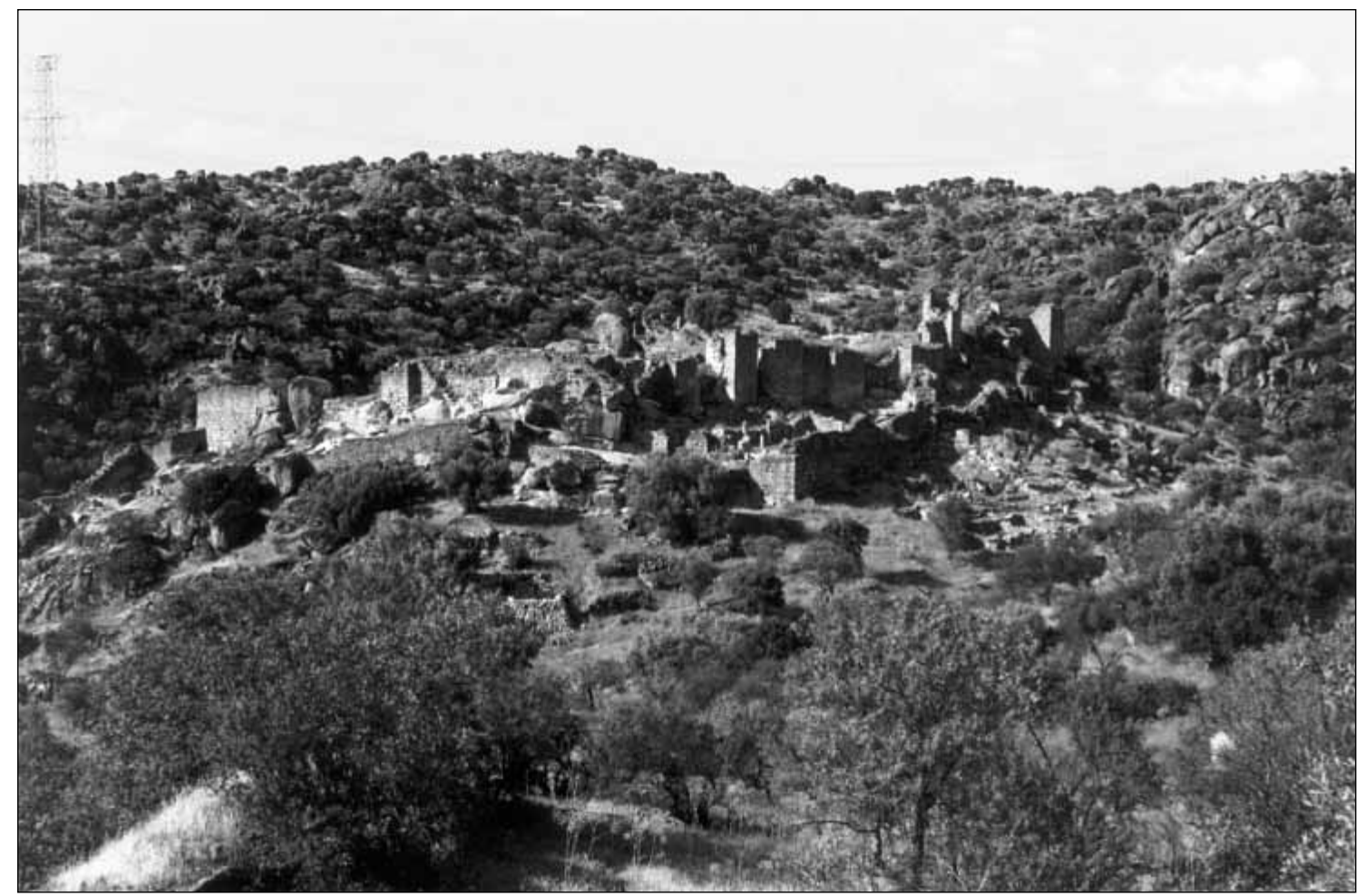

Lámina 7. Vista de la alcazaba desde el interior de la ciudad 


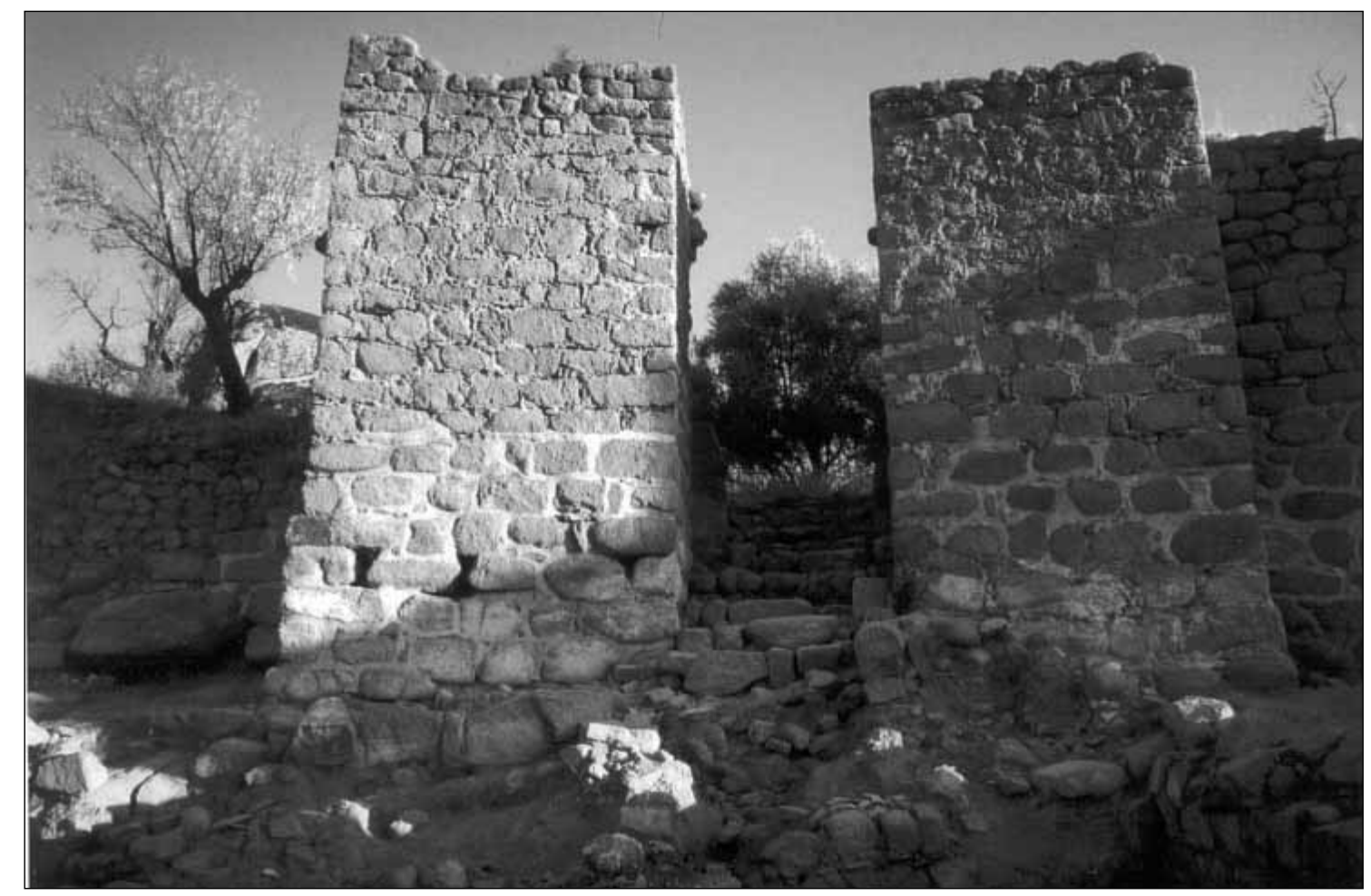

Lámina 8. Entrada al recinto principal de la alcazaba

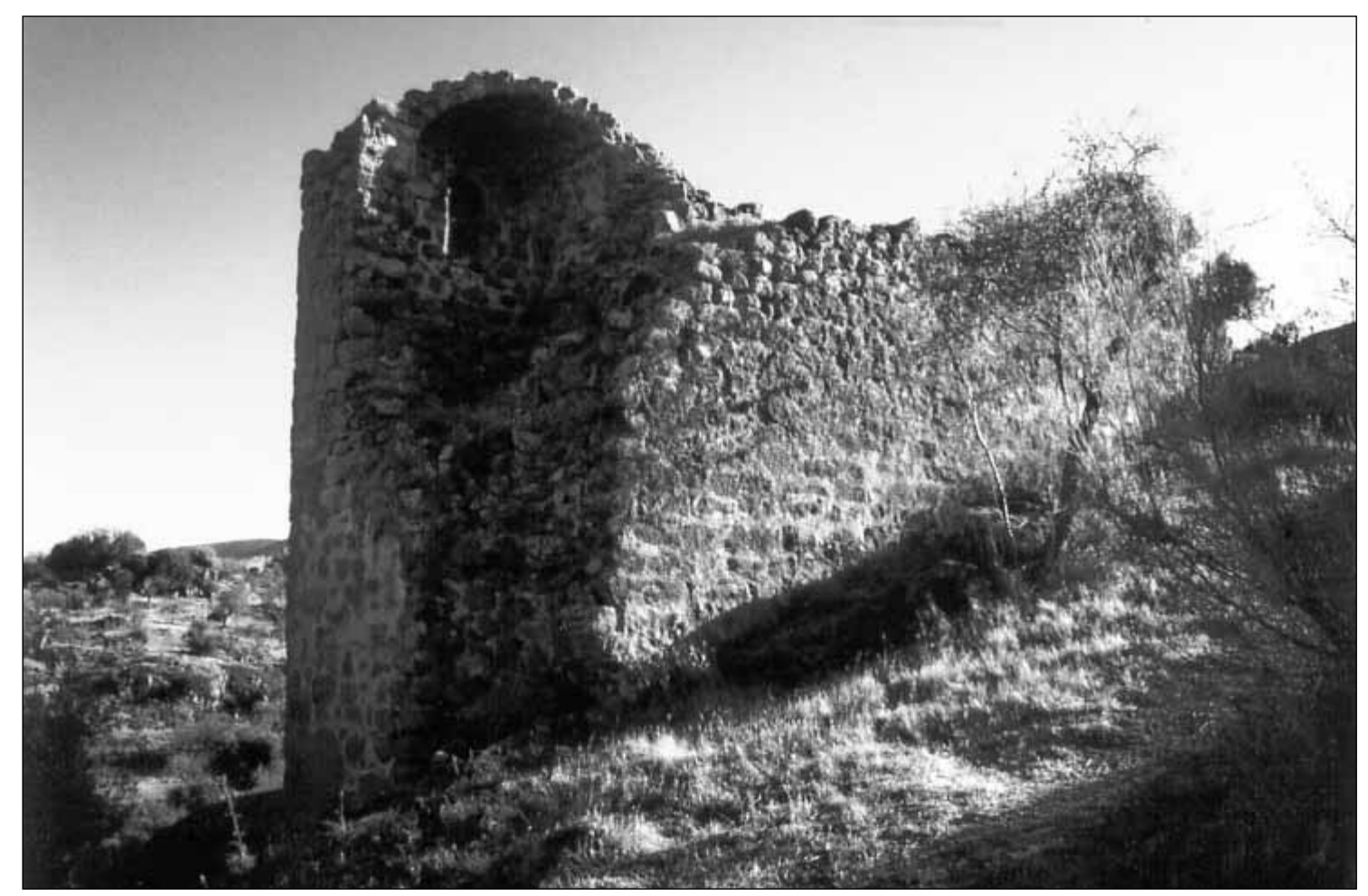

Lámina 9. Torreón de la alcazaba 


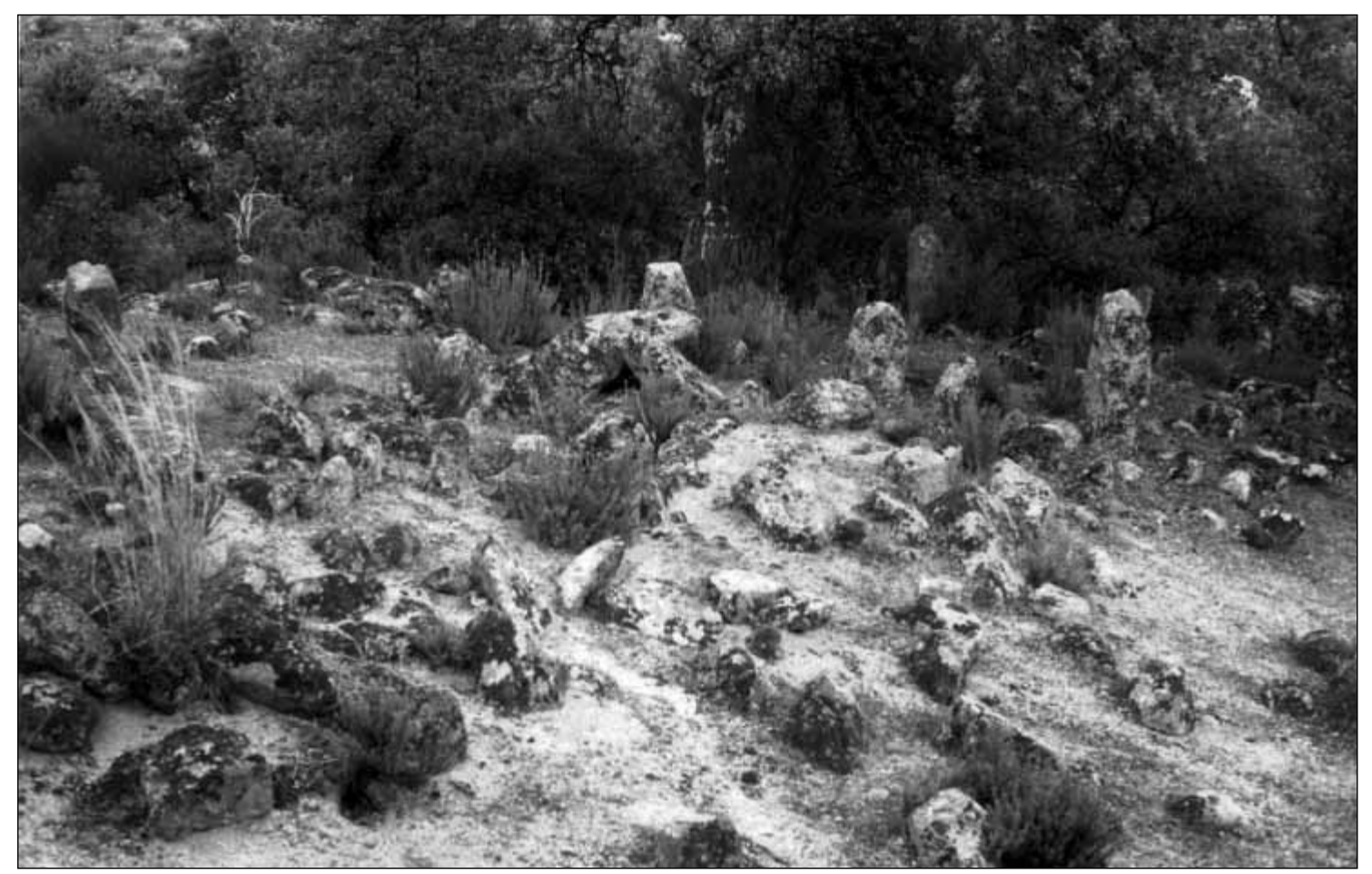

Lámina I0. Vista del cementerio sur

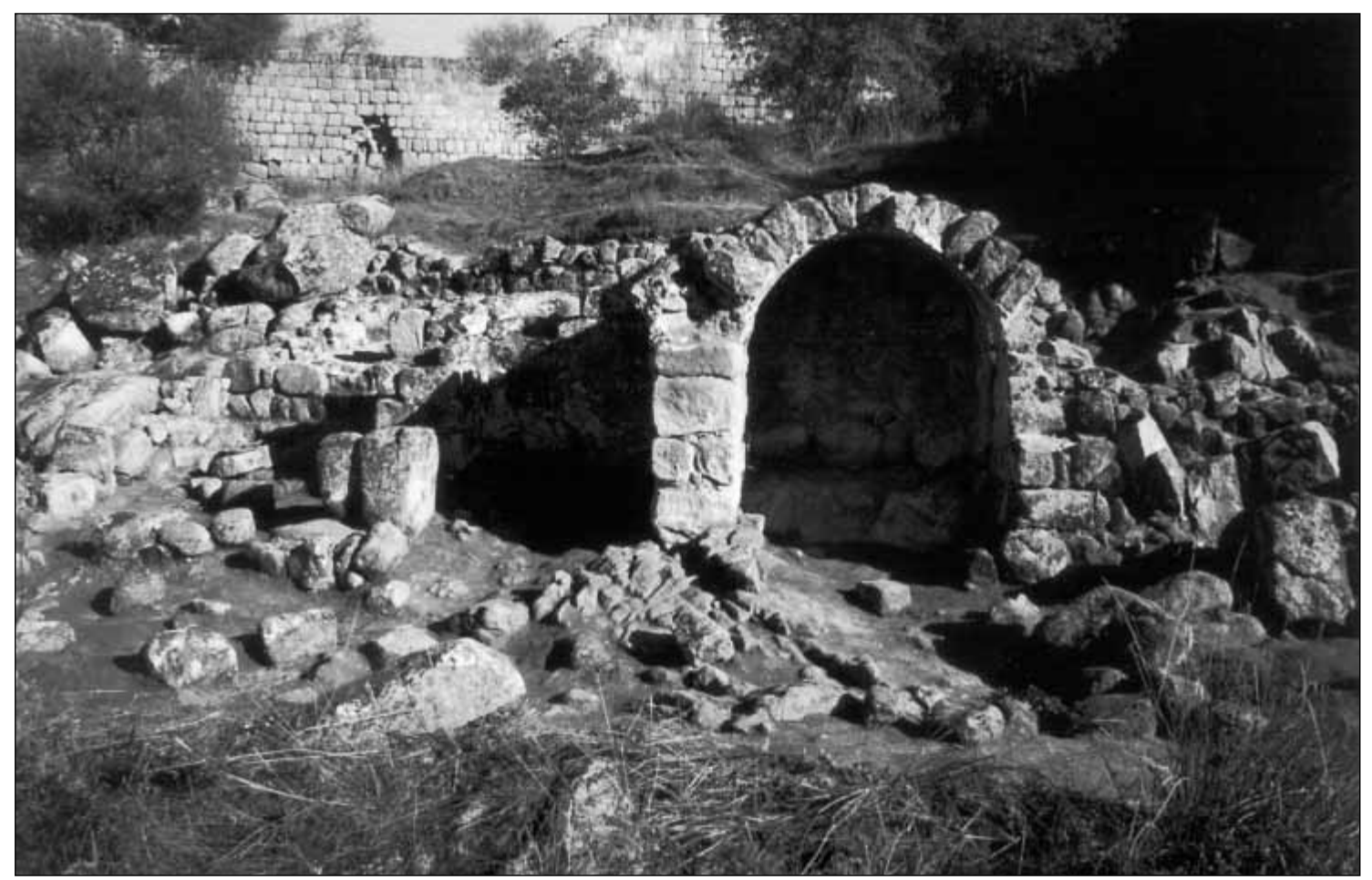

Lámina I I. Restos de los baños 


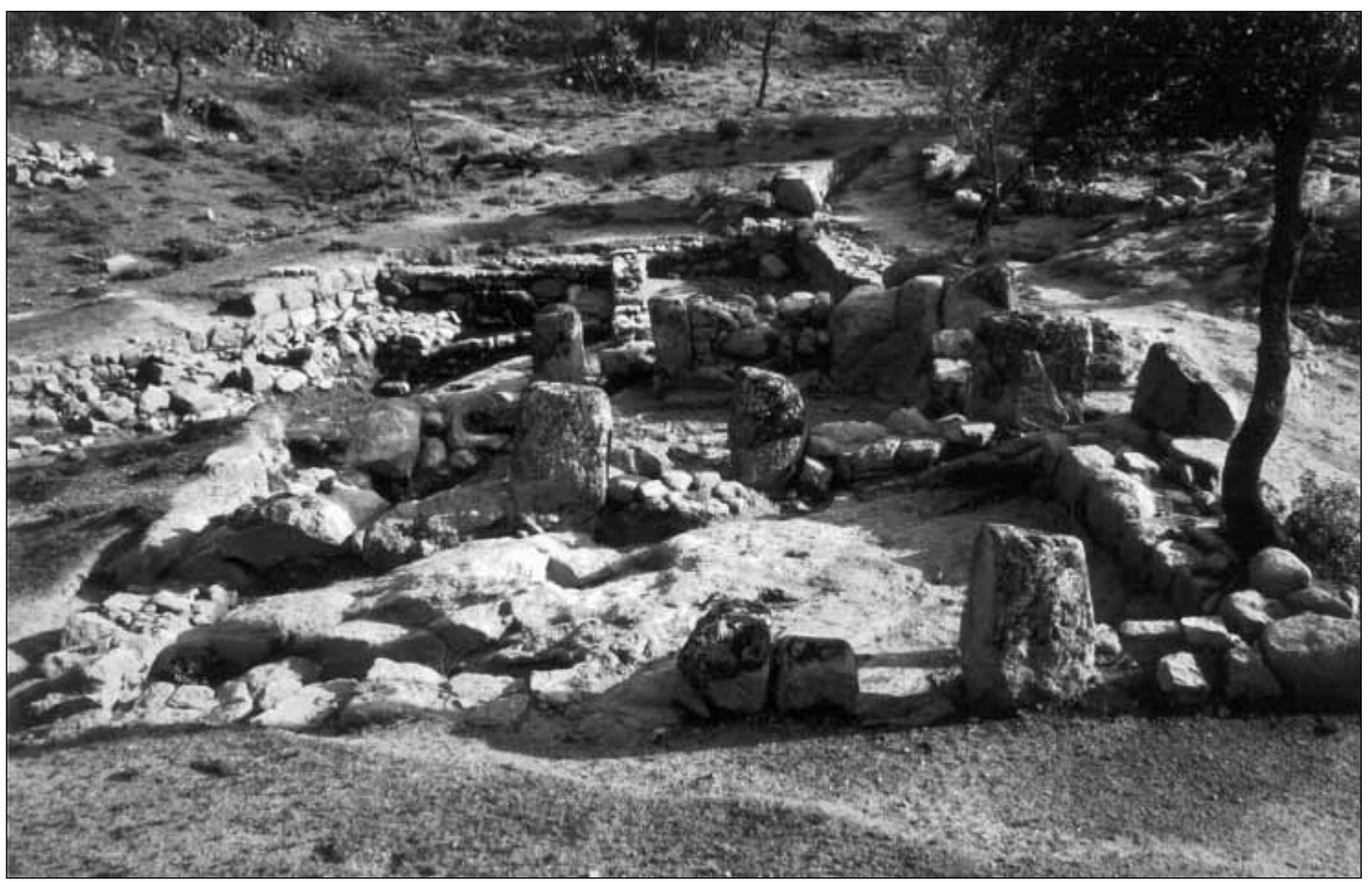

Lámina I2. Vista de la

pequeña mezquita

Lámina I3. Mezquita de la alcazaba

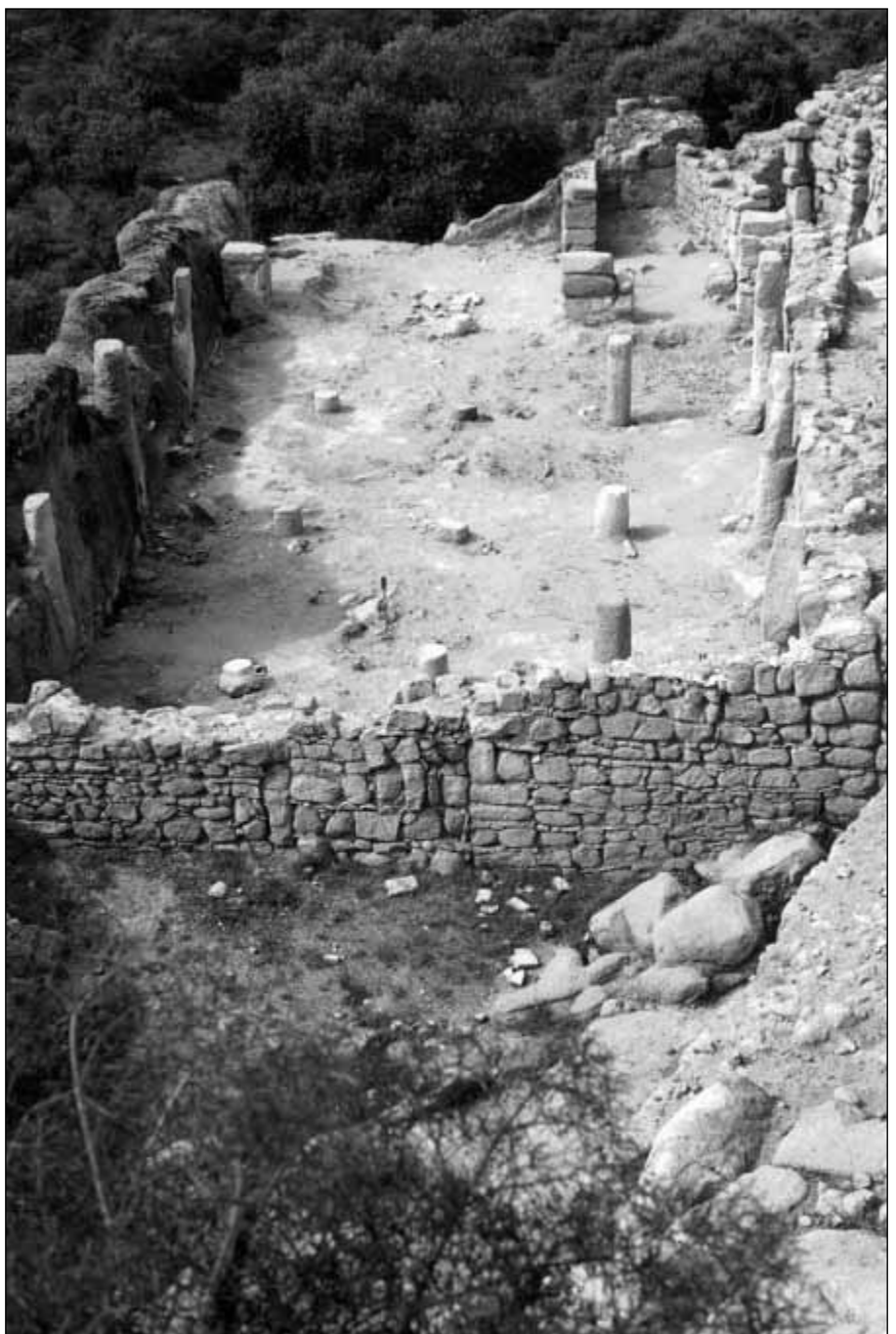

